\title{
Climate responses to SATIRE and SIM-based spectral solar forcing in a 3D atmosphere-ocean coupled GCM
}

\author{
Guoyong Wen ${ }^{1,2, *}$, Robert F. Cahalan ${ }^{1,3}$, David Rind ${ }^{4}$, Jeffrey Jonas ${ }^{5}$, Peter Pilewskie ${ }^{6}$, Dong L. Wu ${ }^{1}$, \\ and Natalie A. Krivova ${ }^{7}$ \\ 1 NASA/Goddard Space Flight Center, Greenbelt, MD 20771, USA \\ ${ }^{*}$ Corresponding author: guoyong.wen@nasa.gov \\ 2 Goddard Earth Sciences Technology and Research/Morgan State University, Baltimore, MD 21251, USA \\ 3 Johns Hopkins University Applied Physics Laboratory, Laurel, MD 20723, USA \\ 4 NASA Goddard Institute for Space Studies, New York, NY 10025, USA \\ 5 Columbia Univeristy, New York, NY 10025, USA \\ 6 Laboratory for Atmospheric and Space Physics, University of Colorado, Boulder, CO 80303, USA \\ 7 Max-Planck-Institut für Sonnensystemforschung, Göttingen 37077, Germany
}

Received 31 January 2016 / Accepted 8 March 2017

\begin{abstract}
We apply two reconstructed spectral solar forcing scenarios, one SIM (Spectral Irradiance Monitor) based, the other the SATIRE (Spectral And Total Irradiance REconstruction) modeled, as inputs to the GISS (Goddard Institute for Space Studies) GCMAM (Global Climate Middle Atmosphere Model) to examine climate responses on decadal to centennial time scales, focusing on quantifying the difference of climate response between the two solar forcing scenarios. We run the GCMAM for about 400 years with present day trace gas and aerosol for the two solar forcing inputs. We find that the SIM-based solar forcing induces much larger long-term response and 11-year variation in global averaged stratospheric temperature and column ozone. We find significant decreasing trends of planetary albedo for both forcing scenarios in the 400 -year model runs. However the mechanisms for the decrease are very different. For SATIRE solar forcing, the decreasing trend of planetary albedo is associated with changes in cloud cover. For SIM-based solar forcing, without significant change in cloud cover on centennial and longer time scales, the apparent decreasing trend of planetary albedo is mainly due to out-of-phase variation in shortwave radiative forcing proxy (downwelling flux for wavelength $>330 \mathrm{~nm}$ ) and total solar irradiance (TSI). From the Maunder Minimum to present, global averaged annual mean surface air temperature has a response of $\sim 0.1{ }^{\circ} \mathrm{C}$ to SATIRE solar forcing compared to $\sim 0.04{ }^{\circ} \mathrm{C}$ to SIM-based solar forcing. For 11-year solar cycle, the global surface air temperature response has 3-year lagged response to either forcing scenario. The global surface air 11-year temperature response to SATIRE forcing is about $0.12{ }^{\circ} \mathrm{C}$, similar to recent multi-model estimates, and comparable to the observational-based evidence. However, the global surface air temperature response to 11-year SIM-based solar forcing is insignificant and inconsistent with observation-based evidence.
\end{abstract}

Key words. Climate response - Spectral solar irradiance - SORCE - SATIRE

\section{Introduction}

Total solar irradiance (TSI) provides the total energy input for the Earth's energy budget at the Top of the atmosphere (TOA). Recent TIM (Total Irradiance Monitor) observations on NASA's SORCE (Solar Radiation and Climate Experiment) satellite provided the most accurate TSI value of $1360.8 \pm$ $0.5 \mathrm{~W} \mathrm{~m}^{-2}$ during the 2008 solar minimum, $4.6 \mathrm{~W} \mathrm{~m}^{-2}$ lower than the value established in the 1990s (Kopp \& Lean 2011; Kopp 2014, 2016). Since that time several other satellite-based TSI observations have improved their instrument corrections, mainly by employing the LASP (Laboratory for Atmospheric and Space Physics) solar irradiance Transfer Radiometer Facility, and these new corrections bring them into closer agreement with TIM (Schmutz et al. 2013; Scafetta \& Willson 2014). In a recent modeling study Rind et al. (2013) show that simulating regional climate change requires that climate models use as input the most accurate (lower) solar irradiance value.

To truly understand solar variations and their influence on Earth's climate, one needs to know, in addition to TSI, also how the spectral solar irradiance (SSI) varies, since the SSI input at different wavelengths plays different roles in the Earth's atmosphere-ocean system. The UV (UltraViolet) spectrum is responsible for heating the stratosphere and stratospheric ozone formation. The VIS (VISible) and near-IR (near-InfraRed) radiation are the major direct energy source to heat the troposphere and ocean. However, the variation of SSI with solar activity is relatively less accurately monitored as compared to the spectrally integrated TSI.

For the first time, the SIM (Spectral Irradiance Monitor) instrument on the SORCE satellite makes daily observations of SSI (Spectral Solar Irradiance) from $200 \mathrm{~nm}$ to $2423 \mathrm{~nm}$, covering almost the entire energy-bearing solar spectrum (i.e., total energy, not energy-per-photon). Harder et al. (2009) found that the SIM VIS and near-IR spectral irradiances have out-of-phase trends with UV and TSI trends in the descending phase of solar cycle 23 , and the variation in UV spectral irradiance is about 4-6 times as large as expected from the NRL (Naval Research Laboratory) empirical model that has in-phase trends for all wavelengths (Lean 2000). Motivated by this discovery, researchers conducted several studies to show that temperature and ozone reponses to SIM-observed spectral solar forcing are quite different from the responses 
to the traditional spectral solar forcing based on the NRL model (e.g., Cahalan et al. 2010; Haigh et al. 2010; Merkel et al. 2011; Ineson et al. 2011; Swartz et al. 2012; Shapiro et al. 2013; Ermolli et al. 2013; Ball et al. 2016).

The SIM observations, and subsequent atmospheric modeling studies, have also initiated a discussion in the Sun climate community regarding whether the SSI variation observed by SIM in the descending phase of solar cycle 23 is real (e.g., Ball et al. 2011; Preminger et al. 2011; Fontenla et al. 2011; Lean \& DeLand 2012; Unruh et al. 2012; Ermolli et al. 2013; Wang et al. 2013; Oberländer et al. 2012; Yeo et al. 2014; Ball et al. 2016; Lee et al. 2016). Wen et al. (2013) show that one can obtain different climate responses when the same SIM data are applied slightly differently, even for the same SIM data and the same climate model. This is partly because the SIM instrument wavelength range of 200-2400 nm covers large but an incomplete portion of TSI (i.e., about $97 \%$ of the TSI in Harder et al. 2009), missing about $40 \mathrm{~W} \mathrm{~m}^{-2}$ beyond the SIM wavelength range. Another issue is that the satellite observation of spectral solar irradiance has lower absolute accuracy as compared to the TIM TSI. With or without having TSI observations as constraint, using different spectral resolution leads to different solar and net radiative forcing, resulting in different surface temperature response. Using SSI for climate study, requires great care in interpreting and implementing TSI budget (see esp. Wen et al. 2013).

Whether the SIM SSI variation is the correct solar variation needs to be validated from independent observations from future missions. However, it is useful to study the implications of climate responses to SIM-like spectral solar forcing, as pointed out in the final section of a review paper by Gray et al. (2010). As the top two priority tasks in Sun-climate further research, they suggested that it is necessary (1) to understand the recent SORCE SIM measurements of spectrally resolved irradiances and assess their implications for solar influences on climate; (2) to determine an accurate value of the total and spectrally resolved solar irradiance during a grand solar minimum such as the Maunder Minimum, when the Sun was in a different mode than during the past few decades.

Climate model results are often used to estimate the climate responses to solar variations and to understand associated mechanisms (e.g., Haigh 1996, 2003; Shindell et al. 1999; Matthes et al. 2006; Meehl et al. 2009; Rind et al. 2008, 2013; Ineson et al. 2011; Frame \& Gray 2010; Gray et al. 2013; Misios et al. 2015; Hood et al. 2015; Kidston et al. 2015; Mitchell et al. 2015). The earlier modeling studies to assess the implication of SORCE SIM measurements mainly focused on the time scale of the 11-year solar cycle by comparing the responses to the out-of-phase SORCE SSI and the in-phase SSI (e.g., NRLSSI and SATIRE SSI). All studies show large differences in atmospheric responses to the out-of-phase and in-phase solar forcing. Though some studies suggest that SORCE SSI strongly overestimates UV solar cycle variability (Lean \& DeLand 2012; Ermolli et al. 2013; Ball et al. 2016), it is not conclusive on which SSI fits ozone observations (Pawson et al. 2014). Note earlier investigations for the implication of SORCE-like SSI on climate focused on solar cycle 23 like variation. Here we investigate the average response to the 11-year cycle over the 1833-2005 period. Furthermore, most of the modeling studies focused on stratospheric and mesospheric temperature and ozone responses. Less attention was paid to surface responses (e.g., Cahalan et al. 2010; Ineson et al. 2012; Wen et al. 2013). One major objective of this study is to access the implication of the SORCE observations on surface temperature on time scales of 400 years and the 11-year solar activity.

In this study, we quantify the difference in climate responses to SIM-like and SATIRE spectral solar forcing from 11-year solar cycle to centennial time scales using the GISS (Goddard Institute for Space Studies) GCMAM (Global Climate Middle Atmosphere Model). In addition to ozone and upper atmospheric responses, we also emphasize quantifying the difference in surface response.

In this paper, we first describe the GISS GCMAM model and the solar forcing experimental design in Section 2. The analysis methods are described in Section 3. The results are presented in Section 4, followed by the summary and discussion in Section 5.

\section{GISS GCMAM and solar forcing experiments}

We design experiments for assessing the implications of SORCE observations for solar influences on climate from 11-year solar cycle to centennial and longer time scales. In this study, we focus on quantifying the difference of climate response to SATIRE modeled and SIM-based spectral solar forcing. We use GISS GCMAM to simulate climate responses to solar variations during some 400 years.

\subsection{GISS GCMAM}

We use the GISS GCMAM (Rind et al. 2007, 2013) to simulate the climate responses to solar variations in this study. This model has been successfully applied for Sun-climate research in the past decade (e.g., Shindell et al. 1999; Rind et al. 2008). The GISS model is a full ocean-atmosphere coupled model with upper boundary at $0.002 \mathrm{mb}(\sim 85 \mathrm{~km})$ with variable resolution. In this study we use $4^{\circ} \times 5^{\circ}$ (lat $\times$ long) with 53 atmospheric layers. The dynamic ocean has 13 layers. As a typical climate model it incorporates all relevant processes, and for the sake of middle atmosphere simulations, it utilizes parameterized gravity wave drag associated with flow over mountains, frontal deformation, convection and shear. With respect to its use for solar experiments described here, the GISS model handles shortwave radiation differently depending upon the spectral interval.

Ozone absorption in the visible Chappuis band $(500-700 \mathrm{~nm})$ is optically thin. It is spectrally averaged and included in the SW (ShortWave) visible band multiple scattering calculations. The ozone UV Hartley-Huggins band $(200-340 \mathrm{~nm})$ absorption is very strong. This absorption is calculated using the path-absorption method whereby the spectral integral of the solar spectrum and ozone absorption coefficients (of order $10 \mathrm{~nm}$ spectral resolution) are spectrally integrated at model initialization (or whenever the solar UV spectrum changes) for broad range of ozone amounts. UV absorption per atmospheric layer by ozone is then calculated along the incident ray path for the local solar zenith angle. For radiation reflected at model cloud-top, the reflected component is assumed to have an effective ray path of twice that in the vertical direction, and the path absorption is continued in the upward direction.

SW absorption by other gases utilizes the $k$-distribution approach. There are 16 pseudospectral correlated- $k$ distribution intervals, which are not spectrally contiguous (Hansen et al. 1983). This absorption is incorporated in the SW calculations that utilize the single gauss point doubling/adding method to 
model the multiple scattering by clouds and aerosols as a function of the local solar zenith angle.

The radiation code for longwave (LW) is based on the $k$-distribution methodology using 33 correlated spectral intervals for troposphere and stratosphere (Lacis \& Oinas 1991; Oinas et al. 2001). Recently, Lacis et al. (2013) showed good agreement of GISS GCM LW fluxes and cooling rates with line-by-line results (see Fig. 11 of Lacis et al. 2013).

As for the mesosphere cooling rate, above $1 \mathrm{mb}$, where the correlated $k$-distribution is not fully resolving the line-by-line spectral absorption, and thus overestimating the absorption, absorber scaling is applied to bring the GCM cooling rate into agreement with line-by-line cooling. The same approach would be applicable to account for any non-LTE (non-local thermodynamic equilbrium) effects.

As ozone responds to varying solar UV, the GCMAM uses the LINOZ (linear interactive model for ozone chemistry) scheme for ozone photochemistry in the stratosphere (McLinden et al. 2000) with an online photochemistry tracer (Rind et al. 2002). All the necessary photochemical agents affecting ozone are include in LINOZ. LINOZ uses the climatology values for the tendency estimation, but does not assume it has to be close to the state of the ozone layer for some particular period of time (personal communication with McLinden). McLinden et al. assessed the validity of the first order approximation and found that "exact tendency" and "linearized tendency" agree pretty well even if the real state differs considerably from the climatology (see Fig. 3 in McLinden et al. 2000).

In the troposphere, ozone is calculated using monthly mean ozone production and loss rates archived from GEOSCHEM, a global photochemical transport mode (see Rind et al. 2007 for more details). This model has been used in the past to determine solar cycle variations in ozone (Rind et al. 2008) with results similar to those from other models as far as ozone and temperature variations are concerned.

\subsection{Solar forcing experiments}

We model climate responses to two solar forcing scenarios in GCMAM. Scenario I is based on SATIRE-T (Spectral and Total Irradiance Reconstructions for the Telescope era) modeled SSI. Hereafter SATIRE-T is referred to as SATIRE for simplicity. SATIRE is a semi-empirical model, employing sunspot numbers to describe temporal changes in solar magnetic activity. See Krivova et al. (2010) for more discussion and appropriate references for the SATIRE model. There are several existing solar irradiance models developed for reconstructing historical SSI (see Ermolli et al. 2013 and Solanki et al. 2013 for details). We choose SATIRE SSI because it has modest variations among other modeled SSI, which are all very different from the SIM observed SSI (see Figs. 2 and 8 in Ermolli et al. 2013).

Scenario II is based on version 19 of SIM observed SSI (Harder et al. 2009 and http://lasp.colorado.edu/home/sorce/ data/ssi-data/). To construct historical SIM-like SSI, we assume here that the spectral profile of the variability relative to TSI variability on time scales of decades to centuries is the same as measured by SIM over the declining phase of cycle 23. We find the relationship between the change of SSI from SIM and the change of TSI from TIM (Total Irradiance Monitor) on the SORCE satellite. We apply the SSI-TSI relationship to change of TSI from SATIRE data to obtain historical SIM-like SSI. We stress that this is an artificial time series which is only constructed with the aim of testing the possible effects of this unconventional profile of SSI variability on Earth's climate.

To do this we first compute the ratio of the change of SIM observed SSI to the change of TIM (Total Irradiance Monitor) observed TSI on the SORCE satellite as expressed in equation (1):

$$
a(\lambda)=\operatorname{SSI}_{\mathrm{SORCE}}(\lambda) / \mathrm{TSI}_{\mathrm{TIM}}
$$

where $\Delta \operatorname{SSI}_{\mathrm{SORCE}}(\lambda)$ and $\Delta \mathrm{TSI}_{\mathrm{TIM}}$ are difference of 10 -day averaged irradiances centered on 21 April 2004 and 7 November 2007, similar to those in Haigh et al. (2010) and Wen et al. (2013), and $\lambda$ is wavelength. In both April 2004 and November 2007 time windows there are no big sunspots. Thus contamination due to rotation is limited. Similar to earlier studies (Haigh et al. 2010; Merkel et al. 2011), we combine irradiance observations from SOLSTICE (SOLar STellar Irradiance Comparison Experiment) (McClintock et al. 2005; 110-240 nm) and SIM (Harder et al. 2009; 240-2430 nm) to make the composite $\operatorname{SSI}_{\text {SORCE }}(\lambda)$.

Note that SIM covers wavelengths up to $2423 \mathrm{~nm}$, not the entire solar spectrum. Though the SIM SSI integrated irradiance is $1324.61 \mathrm{~W} \mathrm{~m}^{-2}$, accounting for $97.3 \%$ of TIMobserved TSI of $1361.33 \mathrm{~W} \mathrm{~m}^{-2}$ similar to Harder et al. (2009), the change of integrated SIM SSI does not equal the change in TSI observed by TIM. Wen et al. (2013) show that SIM cannot provide a sufficiently accurate estimate of TSI mainly because the design of the spectral instrument is not as accurate as the TSI instrument. Thus SIM observations must be complemented by TSI measurements, especially for global climate simulations when the radiation budget is crucial. Here, we apply the total irradiance constraint based on the independent TIM measurements of TSI. In order to ensure that the spectrally integrated SSI is equal to the TSI measured by TIM, the SIM unobserved energy (TIM-observed TSI minus integrated SIM SSI) is evenly distributed across the infrared wavelengths from $0.7 \mu \mathrm{m}$ to $10 \mu \mathrm{m}$ for both April 2004 and November 2007 (for details see Wen et al. 2013).

Using $\triangle$ TSI $_{\text {SATIRE }}$ from historical SATIRE TSI and the spectral to total ratio from SORCE data (Eq. 1), we obtain a SIM-based historical SSI variation in equation (2):

$$
\Delta \operatorname{SSI}_{\text {SORCE }}(\lambda, t)=a(\lambda) \Delta \operatorname{TSI}_{\text {SATIRE }}(t)
$$

Again, the reconstructed historical SIM-based SSI is based on SIM and TIM observations in the descending phase of solar cycle 23, the assumption of stable spectral to total ratio, and the historical variation in SATIRE TSI.

Figure 1 shows the irradiance variations for UV1 $(\lambda<$ $330 \mathrm{~nm})$, UV2 $\quad(330<\lambda<400 \mathrm{~nm}), \quad$ VIS $\quad(400<\lambda<$ $700 \mathrm{~nm})$, SW irradiance $(\lambda>330 \mathrm{~nm})$, and TSI for the two solar forcing scenarios. Since there is little stratospheric absorption for irradiance with wavelength greater than $330 \mathrm{~nm}$, we define the SW irradiance $(\lambda>330 \mathrm{~nm})$ as "SW radiative forcing proxy" in this study. By design, the TSI variation is identical for the two solar forcing scenarios. The SIM-based SSI variation shows 4-6 times larger in-phase variation in UV1 band $(\lambda<330 \mathrm{~nm})$ and out-of-phase variation in VIS compared to the SATIRE reconstructed counterpart, similar to those in multi-year data analysis for SIM SSI and SATIRE SSI (Ball et al. 2011; Yeo et al. 2014) and SIM SSI and NRL SSI (Harder et al. 2009; Haigh et al. 2010). 
(a)

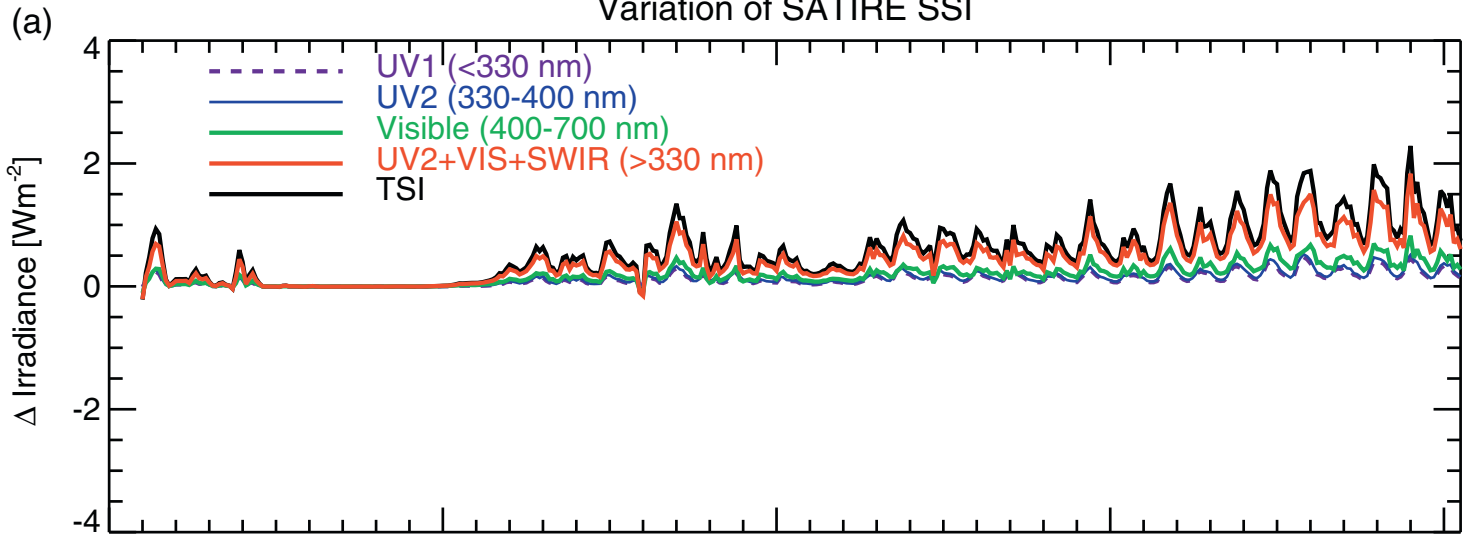

(b)

Variation of SIM-Based SSI

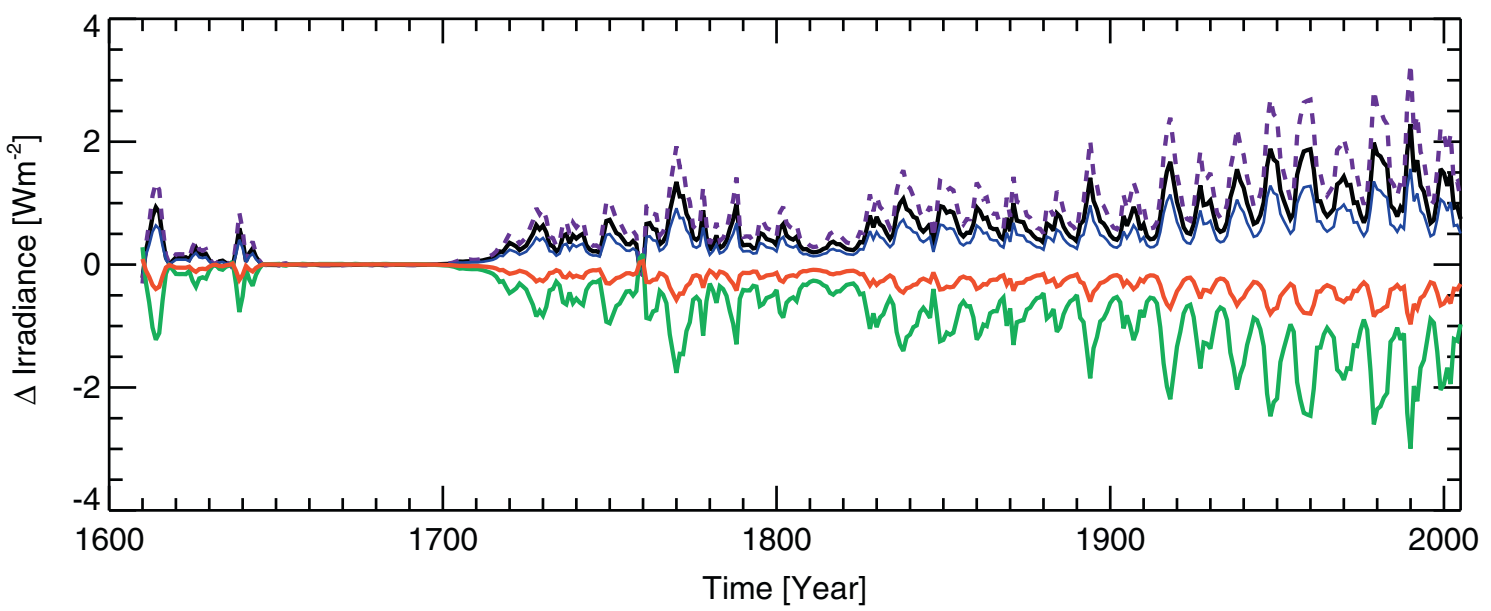

Fig. 1. (a) SATIRE modeled in-phase SSI variations for UV1 $(\lambda<330 \mathrm{~nm})$, UV2 $(330<\lambda<400 \mathrm{~nm})$, visible $(400<\lambda<700 \mathrm{~nm})$, SW radiative forcing proxy $(\lambda>330 \mathrm{~nm})$, and TSI relative to year 1660; (b) similar to (a) but for SIM-based irradiance variations. Note that for the same TSI variations, the amplitude of SIM-based UV $(\lambda<330 \mathrm{~nm})$ irradiance variation is about four times as large as that for SATIRE modeled SSI, SIM-based visible irradiance varies out-of-phase with the UV irradiance, the SIM-based solar forcing proxy is out-of-phase with TSI. From Maunder Minimum to the recent solar minima (1900-2005), TSI increases by $0.72 \mathrm{~W} \mathrm{~m}^{-2}$. In the modern solar maximum period (1900-2005), the TSI 11-year cycle variability is about $0.83 \mathrm{~W} \mathrm{~m}^{-2}$.

This is simply because a constant ratio of change in SSI to the change in TSI derived from equation (1) in SORCE era is applied to equation (2) to obtain the historical variation of SIM-based historical SSI variation. For SIM-based SSI, large out-of-phase VIS variation is compensated to some extent by the in-phase UV2 $(330-400 \mathrm{~nm})$ irradiance variation. As a result, the SW radiative forcing proxy $(\lambda>330 \mathrm{~nm})$ is outof-phase with UV variation at 11-year solar cycles and has a decreasing trend since the Maunder Minimum, opposite of the SATIRE counterpart.

Since SATIRE SSI varies in-phase with solar activity in the UV and visible, we also call solar forcing scenario I as "in-phase solar forcing". And because the visible spectral irradiance of SIM-based solar forcing varies out-of-phase with solar activity, we also call solar forcing scenario II as "out-ofphase solar forcing" in this paper.

We emphasize that in both experiments non-solar forcings are held constant in time. LINOZ, the chemistry model in GISS GCMAM, uses current day distributions of trace gases, and some of these have varied with time since the pre-industrial period, particularly $\mathrm{N}_{2} \mathrm{O}$ and $\mathrm{CH}_{4}$. Most of these changes have occurred, like for $\mathrm{CO}_{2}$, since the 1950 s, and they have routinely been overlooked relative to the variation in UV in studies of the solar variability effect (e.g., Austin et al. 2008). Present day aerosol loading is used for the experiments without considering changes of aerosol due to human activities or volcanic eruptions. Nevertheless, were we actually attempting to simulate the changes since pre-industrial time, that would introduce an error. For example, we also do not vary $\mathrm{CO}_{2}$ with time, and that will also impact stratospheric temperatures and hence ozone production. Thus these are not simulations of solar cycle effects from the pre-industrial time to the present. They are simply experiments that utilize two estimated solar spectral forcing variations over that time period, in simulations of some 400 years.

Were we to really try to simulate those particular solar cycle effects since pre-industrial times, we would need to use all the trace gas and solar changes, as well as aerosol (both tropospheric and volcanic) changes, with a fully coupled atmospheric chemistry model. That is beyond the scope of this paper.

Two control runs, each with (unchanging) pre-industrial solar irradiance appropriate for each of the solar irradiance models used, were simulated for some 500 years. The experiments were then started from year 100 of each of those simulations when the global surface air temperature had already 
G. Wen et al.: Climate responses to SATIRE and SIM-based spectral solar forcing in a 3D atmosphere-ocean coupled GCM

stabilized, thus eliminating any significant differences in "spinup" for this comparison. The control runs were basically used to assess that there were no "drifts", i.e., trends in the runs with unchanging solar irradiance that would have been ascribed to the variations in solar irradiance in either of the two experiments.

\section{Analysis methods}

We analyze GISS GCMAM simulated climate variables, including temperature, ozone, planetary albedo. The main objective of the analysis is to quantify the difference of the GCMAM simulated climate response to the two solar forcing scenarios.

Without changes in greenhouse gases and aerosols, GISS GCMAM simulated climate variation is a combination of the response to solar forcing variation and natural variability. To extract the response component from simulated data, we assume that any given climate variable is a linear function of the input solar forcing. We use TSI variation for the solar forcing in this analysis. For a climate variable, the simulated climate variation (e.g., $\Delta T$ ) and the response to solar forcing (e.g., $\beta \Delta \mathrm{TSI})$ are linearly related by:

$$
\Delta T=\beta \Delta \mathrm{TSI}+\varepsilon
$$

where $\beta$ is the sensitivity of the response to the forcing $\Delta$ TSI and $\varepsilon$ is error variable. The sensitivity parameter $\beta$ is determined by minimizing the sum of squared differences between the responses (i.e., $\beta \Delta \mathrm{TSI}$ ) in equation (3) and those from GCMAM simulations (i.e., $\Delta T$ ) in equation (4):

$$
Q=\sum_{i=1}^{N}\left(\beta \Delta \operatorname{TSI}\left(t_{i}\right)-\Delta T\left(t_{i}\right)\right)^{2}
$$

In practice, we define $\Delta \operatorname{TSI}(t)=\operatorname{TSI}(t)-\operatorname{TSI}\left(t_{0}\right)$ in the irradiance data and $\Delta T(t)=T(t)-T\left(t_{0}\right)$ from GCM simulation, where $t_{0}$ is an arbitrary reference time, and we choose $t_{0}=1611$ in this analysis. We further use the Student's $t$-test to examine whether the response from regression is significant. The correlation coefficients between the GCM simulated climate variation and the response are also computed to indicate the significance of the regression results. The results from this analysis are presented in Sections 4.1-4.3.

We use this method to extract global averaged annual mean climate variables, including temperatures at different altitudes, total column ozone amount, and planetary albedo in this analysis. Figure 2 shows an example of this method for global averaged annual mean temperature response at $15 \mathrm{mb}$. It is clear that the response, characterized by the sensitivity parameter, for SIM-based solar is about six times as large as that for its counterpart of SATIRE forcing. The correlation for the outof-phase solar forcing is 0.95 compared to 0.44 for the in-phase solar forcing.

The advantage of this method is that it takes care of long-term trend and cyclic decadal variability of atmospheric physical parameter driven by solar forcing. Since changes in TSI are the same for the two experiments, the sensitivity parameter is the relative magnitude of the response. The disadvantage is that the sensitivity may not represent true responses when a physical parameter does not respond linearly with the solar forcing. For example, the ocean has large heat capacity. Thus the surface temperature will have a delayed response to the solar forcing. And this will be treated differently.

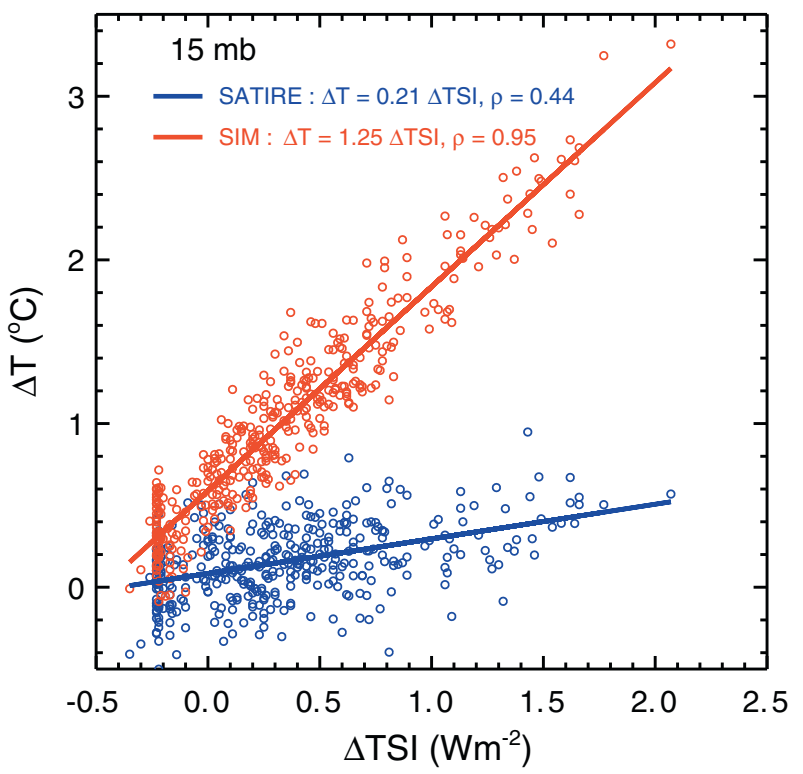

Fig. 2. An example to show the regression analysis to extract temperature response to solar forcing at $15 \mathrm{mb}$.

Climate response to 11-year solar activity is of special interest in the Sun-climate community. We will present climate responses to the two solar forcing scenarios. Sunspots have been observed since 1610, the beginning of the telescopic era. The sunspot number is a key parameter for reconstructing historical solar irradiance (e.g., Lean 2000; Krivova et al. 2010). For identifying solar maximum and solar minimum years, we use the same sunspot number data used for SATIRE reconstruction.

We examine the zonal averaged annual mean atmospheric responses to 11-year solar activity starting from 1833 after Dalton Minimum. There are 16 solar cycles in this time period. In analysis process, we first find solar maximum and solar minimum years from the sunspot number record. To reduce internal variability, we use 3-year average values around the maximum and minimum years. The response of an atmospheric parameter (e.g., temperature, ozone) to a particular 11 -year solar cycle variation is defined to be the difference between its value in a solar maximum year and that in that cycle's solar minimum year (i.e., solar maximum minus solar minimum). Then we compute the average 11-year response by averaging over 16 solar cycle differences. We examine the average response in this study. The results from this analysis are presented in Sections 4.4-4.5.

Special attention is required for the global averaged annual mean surface air temperature response to 11-year solar activity in the 1833-2005 period. Since the ocean has large heat capacity, the surface temperature will have a delayed response to the solar forcing. We performed a regression analysis to the global average temperature anomalies to the TSI variations using a similar method to that in Misios et al. (2015). Since we are only interested in 11-year solar cycle variation, we filter out long-term trends of both TSI and temperature. We perform linear regression of global temperature with lagged TSI. In this process, TSI is shifted forward (positive) and backward (negative). The number of lag/lead step ranges from -5 to 5 years, with increments of one year. Lag zero is for in-phase variation of the temperature signal and solar forcing. Positive lag is for solar forcing leading the temperature response. Negative lag is 
for solar forcing lagging the temperature response. The regression coefficient is computed for each shifted TSI. All the regression coefficients are scaled to a $1 \mathrm{~W} \mathrm{~m}^{-2}$ change from solar minimum to solar maximum. We use a two-tailed Student's $t$-test to infer the significance level of the regression coefficient (the slope), taking into account the "equivalent sample size" to eliminate effects of serial correlation (Zwiers $\&$ von Storch, 1995). The results from this analysis are presented in Section 4.6.

\section{Results}

We first examine the global averaged responses for temperature, ozone, and planetary albedo since the Maunder Minimum. Then we analyze atmospheric responses to 11-year solar activity for two solar forcing scenarios.

\subsection{Temperature responses since Maunder Minimum}

Figure 3 shows the GCMAM simulated global averaged annual mean temperature variations and responses extracted from the regression analysis (Eq. 3) for the two solar forcing scenarios at different altitudes in the atmosphere. The temperature response is more sensitive in the upper stratosphere $(2 \mathrm{mb})$ than in the middle stratosphere $(15 \mathrm{mb})$, by a factor of two for both solar forcing scenarios. The warming in the upper stratosphere is closely related to the UV irradiance changes, and this feature is visible from the observations and many model studies (e.g., Frame \& Gray 2010; Remsberg 2008).

The sensitivity parameters (i.e., $\beta$ in Eq. 3), and therefore the temperature responses, for SIM-based solar forcing are about six times as large as that for SATIRE modeled solar forcing. This is because the UV irradiance variation, the driving force for the stratospheric temperature variation, for SIM-based solar forcing is about six times as large as that for SATIRE modeled solar forcing.

From Maunder Minimum to recent minima during Modern Maximum, there is an increase of about $0.72 \mathrm{~W} \mathrm{~m}^{-2}$ in TSI. From the sensitivity parameters, one may easily obtain associated temperature responses. For SIM-based solar forcing, there is an increase of about $1.7{ }^{\circ} \mathrm{C}$ and $0.9^{\circ} \mathrm{C}$ in global and annual averaged temperature in the upper and lower stratospheres, respectively. There is much smaller temperature increase, i.e., $0.27{ }^{\circ} \mathrm{C}$ and $0.15^{\circ} \mathrm{C}$, for SATIRE solar forcing in the same region of the atmosphere.

The average of 11-year TSI variation in Modern Maximum period is about $0.84 \mathrm{~W} \mathrm{~m}^{-2}$. For SIM-based solar forcing, the temperature response to 11 -year solar activity is about $2{ }^{\circ} \mathrm{C}$ and $1{ }^{\circ} \mathrm{C}$ for the upper and lower stratosphere, respectively. For SATIRE forcing, the global averaged annual temperature response is about one sixth of that for the SIM-based solar forcing in the same altitude of the atmosphere.

At $100 \mathrm{mb}$, the long-term change and 11-year response are still strong for SIM-based solar forcing, about four times large as those for SATIRE forcing. There are two factors responsible for the larger response for SIM-based forcing. One mechanism is related to deceleration of the Brewer-Dobson circulation during the enhancement of UV SSI, leading to a dynamically induced positive temperature anomaly in the lower stratosphere (e.g., Matthes et al. 2006). A second mechanism is due to excessive stratospheric warming due to large UV irradiance variations. It is interesting to note that for SIM-based solar forcing (1) on centennial and longer time scales the increase of TOA UV1 $(\lambda<330 \mathrm{~nm})$ irradiance variations is accompanied by a decrease in the SW radiative forcing proxy $(\lambda>330 \mathrm{~nm}) ;(2)$ the in-phase 11-year variation of the UV is associated with an out-of-phase variation in the SW radiative forcing proxy (Fig. 1). The excessive heating of the stratosphere by SIM-like UV irradiance variations leads to an increase in downward longwave radiation to warm the bottom layer of the stratosphere at $100 \mathrm{mb}$, and also the troposphere and surface.

Using a radiative convective model (RCM) Wen et al. (2013) show that even when the SIM-based SW radiative forcing $(0.33-10 \mu \mathrm{m})$ is out-of-phase with solar activity, the surface temperature has a small in-phase response. The surface temperature response increases with increase of ozone amount for the SIM-like solar forcing (see Fig. 6 for SSF3 in Wen et al. 2013). This confirmed that SIM-based solar forcing induces a larger downward longwave radiative forcing compared to the in-phase solar forcing such that the net radiative forcing is positive. Note the RCM is a simple 1D model without dynamics and chemistry. Thus the relatively large response to SIM-based solar forcing at $100 \mathrm{mb}$ is the result of combination of a excessive heating of the stratosphere and the dynamically induced heating in the GCM simulation.

At the surface, the sensitivity of the temperature response to SIM-based solar forcing is about $0.05{ }^{\circ} \mathrm{C} /\left(\mathrm{W} \mathrm{m}^{-2}\right)$, less than half of that for SATIRE modeled solar forcing. From Maunder Minimum to the recent solar minima, for SIM-based solar forcing, there is an increase of about $0.04{ }^{\circ} \mathrm{C}$ in surface temperature compared to $0.1{ }^{\circ} \mathrm{C}$ increase for SATIRE modeled solar forcing for the same amount of change of $0.72 \mathrm{~W} \mathrm{~m}^{-2}$ in TSI. Again, the SIM-based SW radiative forcing proxy varies out-of-phase with solar activity. From Maunder Minimum to the recent, SIM-based SW radiative forcing proxy has a decrease of $-0.3 \mathrm{~W} \mathrm{~m}^{-2}$ compared to an increase of $0.6 \mathrm{~W} \mathrm{~m}^{-2}$ for conventional in-phase SATIRE solar forcing. The out-of-phase solar forcing does not necessarily induce an out-of-phase surface temperature response. For the SIMbased solar forcing, both excessive stratospheric heating and associated dynamic change work to induce an in-phase temperature response at the surface.

\subsection{Total column ozone responses}

Figure 4 shows the GISS GCMAM modeled time series of global averaged annual mean column total ozone variations and the responses from the regression analysis for the two solar forcing scenarios. Global total ozone response for SIM-based solar forcing is about six times as large as that for SATIRE forcing. From the grand Maunder Minimum to the recent minima there is $\sim 17$ DU (Dobson Unit) ( $\sim 6 \%$ in global average value of $\sim 300$ DU) increase in total ozone amount for SIM-based solar forcing compared to $\sim 3$ DU $(\sim 1 \%)$ response to SATIRE forcing.

Over the Modern 20th century maximum, the total column ozone response to 11-year solar activity is pronounced for SIM-based solar forcing, with amplitude of 10-30 DU (3 10\%) compared to amplitude of 4-6 DU (1 1.7\%) for SATIRE solar forcing. The average response to 11 -year solar activity is about 20 DU $(\sim 7 \%)$ for SIM-based solar forcing compared to $\sim 3.3 \mathrm{DU}(\sim 1 \%)$ for SATIRE solar forcing. The observational evidence of $1-3 \%$ variation to 11 -year cycle suggests that SORCE SSI overestimates UV solar variability 
G. Wen et al.: Climate responses to SATIRE and SIM-based spectral solar forcing in a 3D atmosphere-ocean coupled GCM

(a)
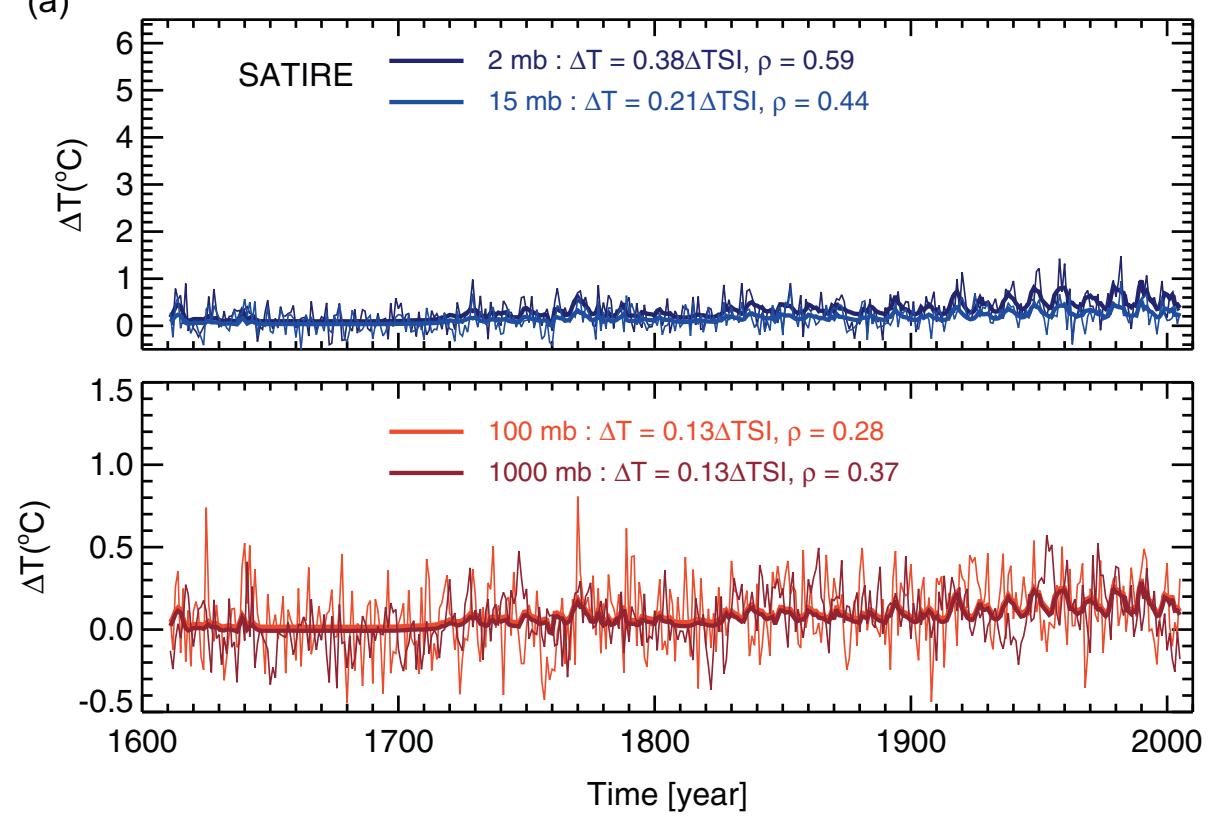

(b)
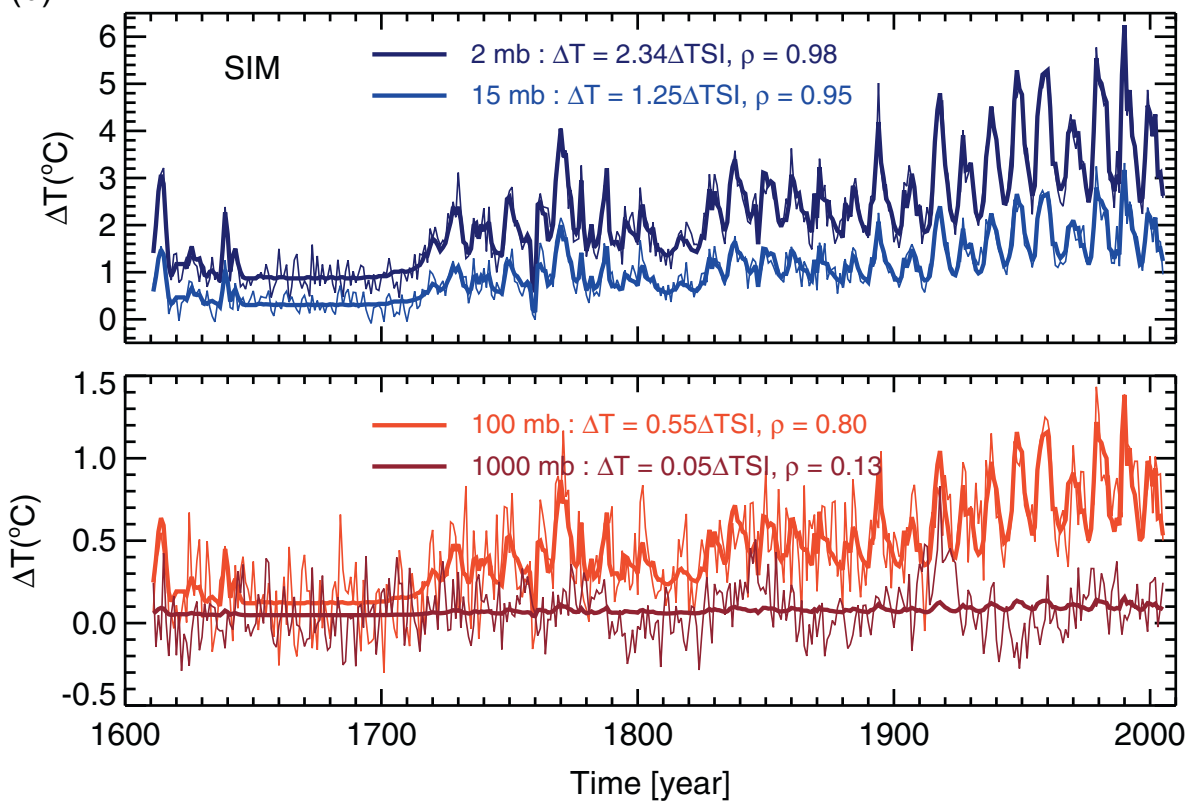

Fig. 3. (a) Simulated global averaged annual mean temperature variations (thinner lines) for SATIRE spectral solar forcing and the responses extracted from the regression analysis of the modeled data (thicker lines) for different altitudes. Correlation coefficients between modeled variation and response from regression analysis are indicated. (b) Simulated global averaged annual mean temperature variations (thinner lines) for SIM-based spectral solar forcing and the responses extracted from the regression analysis of the modeled data (thicker lines) for different altitudes. Correlation coefficients between modeled variation and response from regression analysis are indicated.

to some extent as reported in a WMO ozone report (Pawson et al. 2014).

\subsection{Planetary albedo responses}

A significant portion of the surface air temperature response is associated with the climate feedbacks in the system, water vapor increasing and sea ice decreasing as climate warms. A major uncertainty though is associated with cloud cover. Here we examine annual mean planetary albedo responses to the two solar forcing scenarios, which are dominated by the cloud cover changes. Figure 5 presents the modeled planetary albedo changes and the responses from regression analysis for both forcing scenarios. It is evident that the planetary albedo has variability about $0.2 \%$ on multi-decadal time scale for both forcing scenarios. The albedo response to solar forcing identified from regression analysis is negative for SATIRE and SIM-based solar forcing. On multi-decadal time scale, without direct relation with solar forcing, the variation in the albedo is due to natural variability and/or non-linear response to the solar forcing. Thus the response from regression analysis is a better representation on centennial and longer time scale.

From Maunder Minimum to the recent minima, there is a decrease in planetary albedo for both forcing scenarios. However, the mechanisms for the decrease are quite different. Here we examine total cloud cover (mainly due to low cloud) 
Global Total Ozone Responses

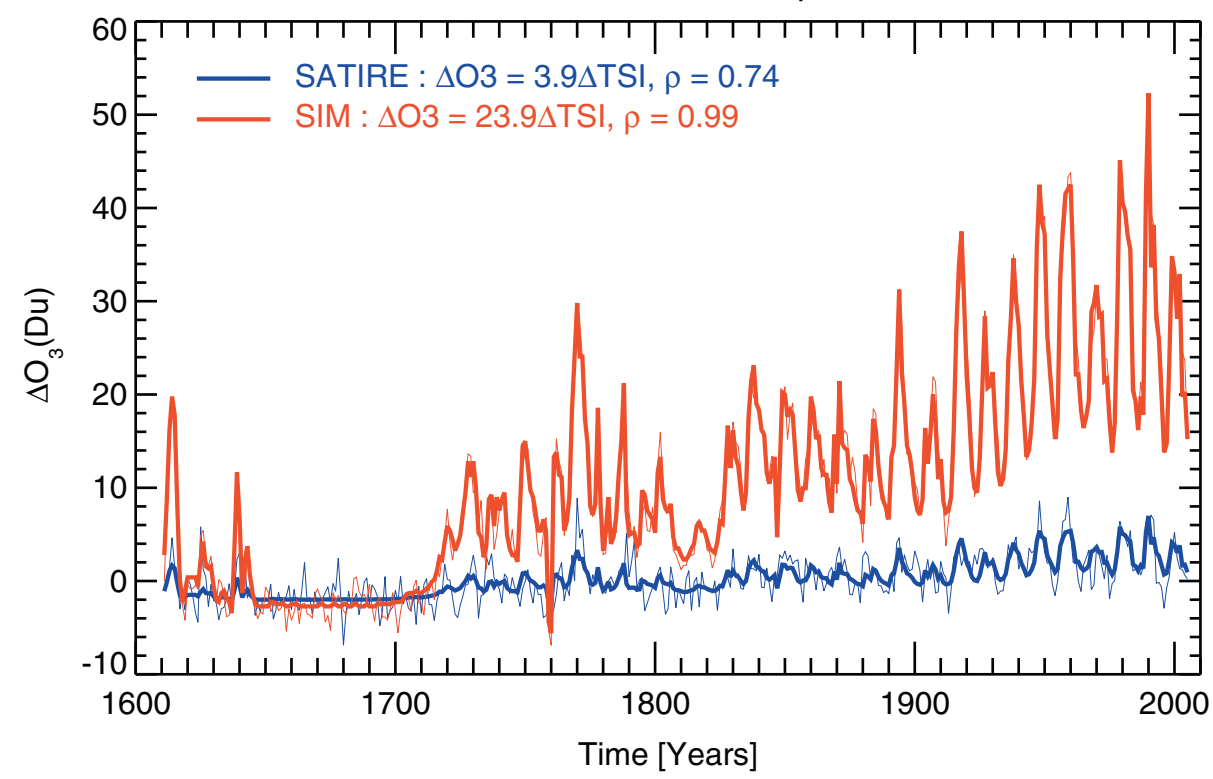

Fig. 4. Simulated global averaged annual mean total column ozone variations (thinner lines) and the responses extracted from the regression analysis (thicker lines) for SATIRE (blue) and SIM-based (red) solar forcing, respectively.

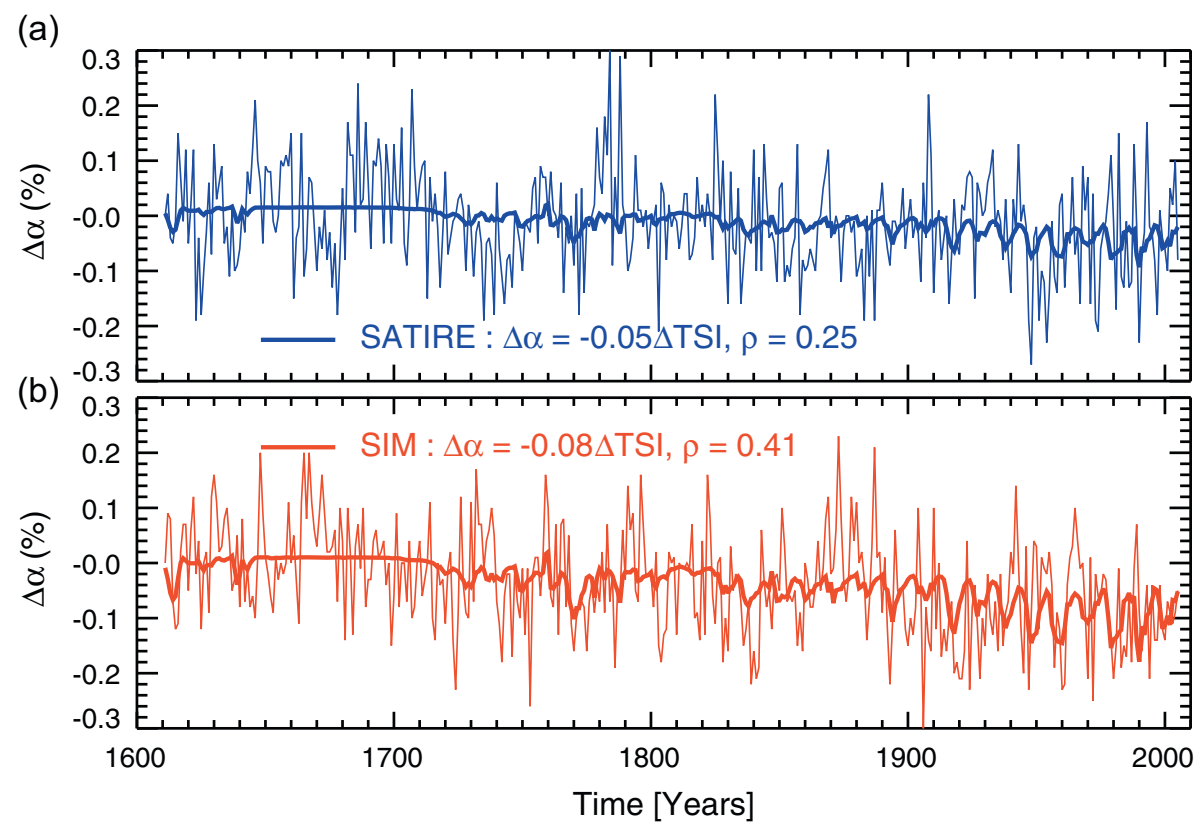

Fig. 5. (a) Simulated global averaged annual mean planetary variations (thinner lines) and the responses extracted from the regression analysis (thicker lines) for SATIRE (blue); (b) similar to (a) but for SIM-based (red) solar forcing. The regression analysis show than the planetary albedo has negative response to the two solar forcing.

in Figure 6. For SATIRE forcing, the decreasing trend in cloud cover is about $-0.03 \%$ /century at $90 \%$ significance level. The cloud cover trend for SIM-based forcing is negligible. In most climate models, as the surface warms, low clouds (and total clouds) decrease. It is shown in Figure 3 a that SATIRE has a greater surface warming, therefore it would be expected to have a greater decrease in low cloud cover as see in Figure 6 a. With the smaller warming in the SIM simulation, the response in cloud cover is much smaller. This suggests that the trend in planetary albedo for SIM-based forcing is not related to the cloud feedback, rather is it mainly due to the decrease of the SW radiative forcing (Fig. 1) while the TSI increases, as described below.

The albedo is the ratio of reflected and incident solar radiation:

$$
\alpha=\frac{F \uparrow}{F \downarrow}=\frac{F \uparrow}{\mathrm{TSI}}
$$

where $F \downarrow$ and $F \uparrow$ are incident and reflected solar irradiance at TOA. Since little amount of UV radiation below wavelength 
G. Wen et al.: Climate responses to SATIRE and SIM-based spectral solar forcing in a 3D atmosphere-ocean coupled GCM

(a)

Total Cloud Cover Responses

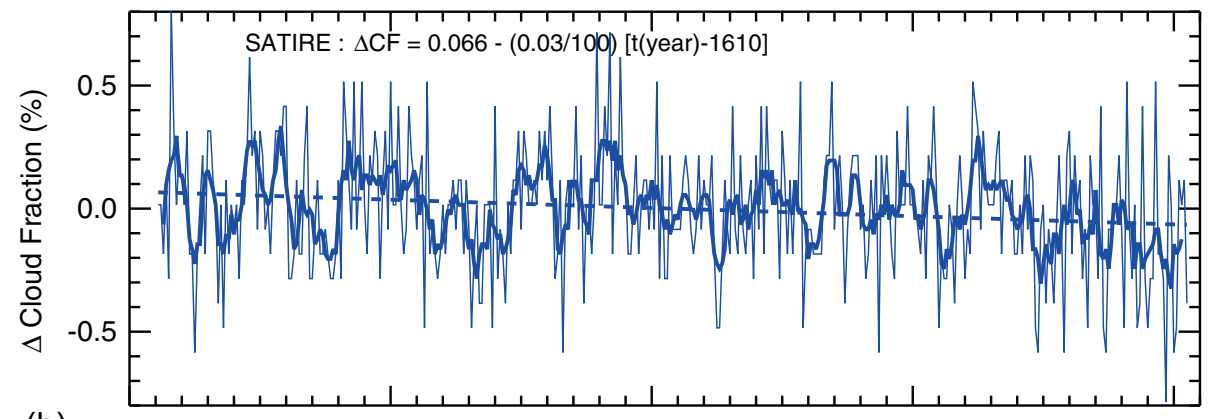

(b)

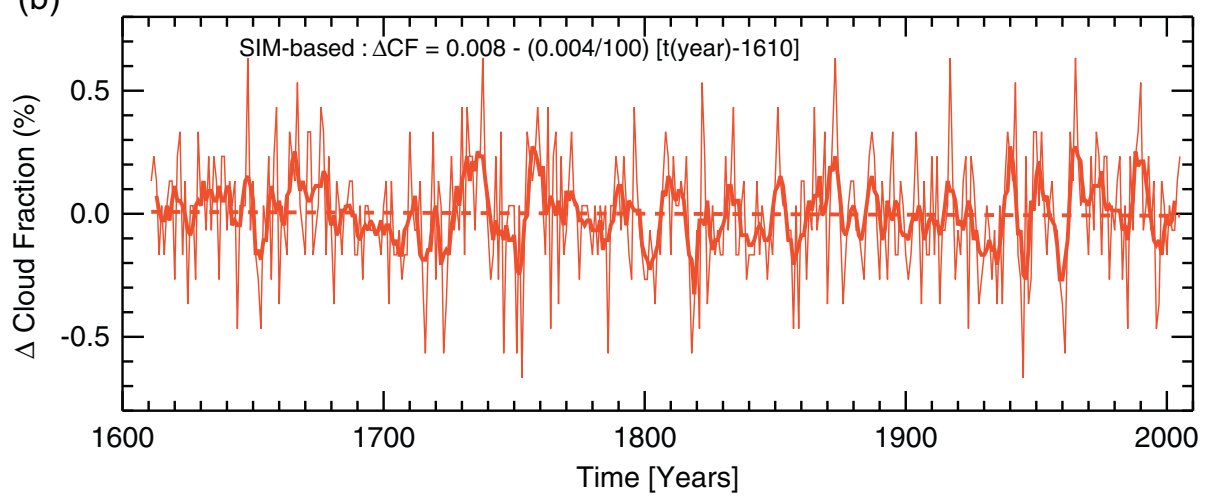

Fig. 6. Cloud cover responses to SATIRE modeled (blue) and SIM-based (red) spectral solar forcing (thinner lines for annual average and thicker lines for 5 -year running average). The decreasing trend of $-0.03 /$ century for SATIRE forcing is statistically significant. The trend for SIM-based solar forcing is insignificant.

$330 \mathrm{~nm}$ can penetrate to the troposphere, the reflected irradiance, and therefore the albedo, depends on the SW radiative forcing proxy and its fraction to the TSI.

$$
\alpha=\frac{F \uparrow}{\mathrm{TSI}}=\frac{F_{\text {proxy }}}{\mathrm{TSI}} \frac{F \uparrow}{F_{\text {proxy }}}
$$

where $F_{\text {proxy }}$ is SW radative forcing proxy, i.e., $F_{\text {proxy }}=$ $F \downarrow(\lambda>330 \mathrm{~nm})$. Without change in cloud fraction for SIM-based solar forcing experiment, the ratio of $F \uparrow / F_{\text {proxy }}$ would not have a trend on centennial and longer time scales. The change in the irradiance ratio of $F_{\text {proxy }} /$ TSI alone may explain the change of planetary albedo on centennial and longer time scales.

Figure 7 shows the time series of irradiance ratio of $F_{\text {proxy }} /$ TSI for the two forcing scenarios. From Maunder Minimum to the recent minima during the modern solar maximum (1900 to present), the ratio is almost a constant for SATIRE solar forcing. For SIM-based solar forcing, however, there is a decrease about $0.06 \%$ in the ratio as a result of increase in TSI and decrease in $F_{\text {proxy }}$ since Maunder Minimum to the minima in modern solar maximum. In fact, one may compute the albedo response using regression equation $\Delta \alpha=-0.08 \Delta$ TSI with $0.72 \mathrm{~W} \mathrm{~m}^{-2}$ for the change of TSI from Maunder Minimum to the minima of modern solar maximum. The result is consistent with the estimate from the change in the ratio $F_{\text {proxy }} /$ TSI from Maunder Minimum to modern minima.

It is interesting to note that there is a weak but positive surface temperature response for the out-of-phase forcing scenario even though SW radiative forcing proxy has a decreasing trend since Maunder Minimum. This is a characteristic feature of surface response to SIM-based solar forcing.

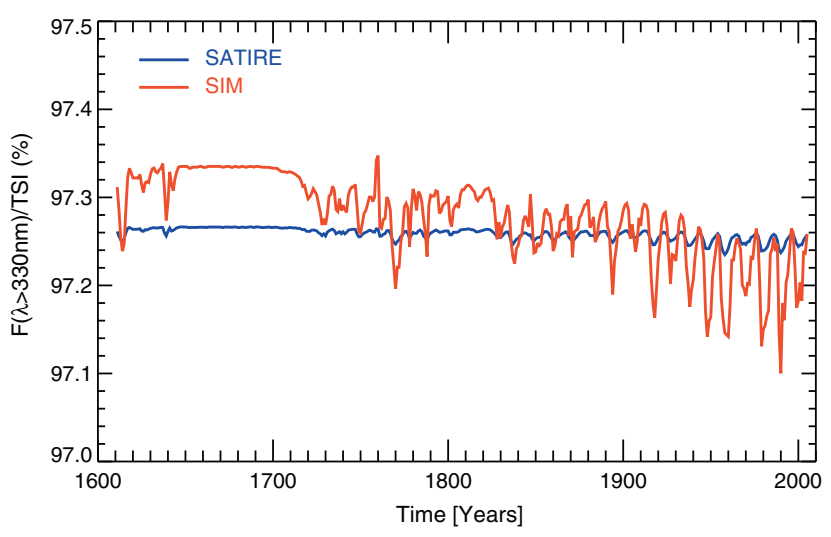

Fig. 7. Change of the ratio of SW radiative forcing proxy $(\lambda>330 \mathrm{~nm})$ to the TSI for SATIRE (blue) and SIM-based forcing scenarios, respectively. From Maunder Minimum to present solar minima (1900-2005), there is a decrease about $0.06 \%$ in the ratio for SIM-based solar forcing. No significant change in the ratio for SATIRE.

As discussed earlier, excessive stratosphere heating of SIMbased forcing contributes impact surface positive surface response through radiative effect (Wen et al. 2013) and indirect effect through top-down wave propagation (e.g., Kodera \& Kuroda 2002; Matthes et al. 2006; Gray et al. 2010, 2013).

\subsection{Ozone responses to 11-year solar activity}

The averaged percentage ozone responses are presented in Figure 8 with significant level at one and two standard level indicated. It is clear that atmospheric ozone has positive response to 11-year solar activity for both forcing scenarios. 

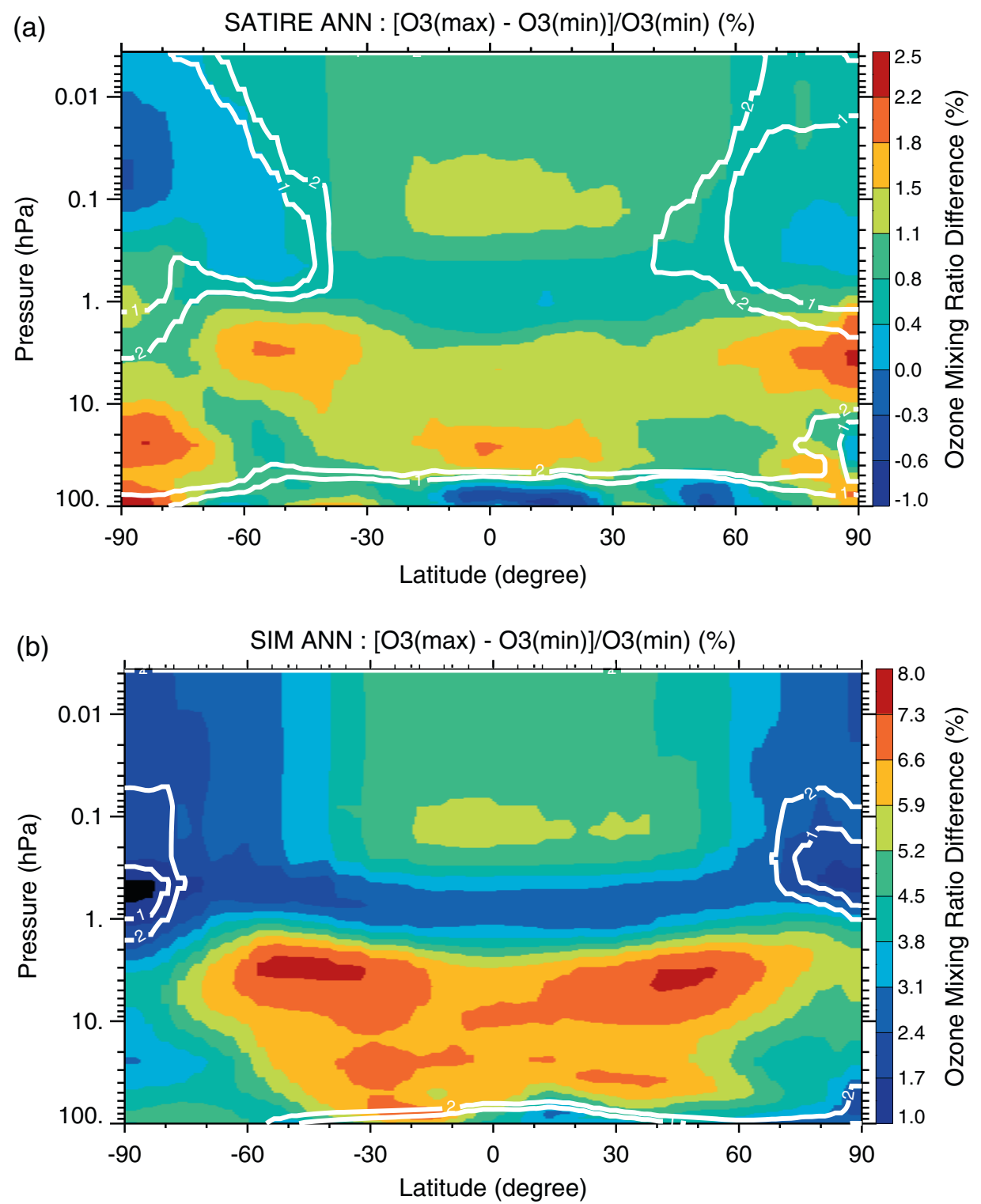

Fig. 8. (a) Average response of zonal-annual mean ozone to 11-year cycle of SATIRE forcing; (b) the response to SIM-based solar forcing.

The response is significant in most regions of the atmosphere for both forcing scenarios, except in the polar upper stratosphere and mesosphere and lower stratosphere.

The ozone changes are the result of altered UV radiation absorption and altered atmospheric dynamics. The ozone response to the two forcing scenarios has similar vertical structures. In latitudes $45{ }^{\circ} \mathrm{S}-45^{\circ} \mathrm{N}$, both responses have a maximum in the stratosphere near $5 \mathrm{mb}$, a local minimum near the stratopause, and a maximum in the mesosphere. However the amplitude of ozone response to the SIM-based solar forcing is much larger than that to the SATIRE solar forcing. In the mid-stratosphere, ozone response to SIM-based solar forcing is $\sim 4-5.5 \%$ compared to $\sim 0.8-1.7 \%$ of ozone response for the SATIRE modeled solar forcing. Note the model is able to simulate partially the observational based "double-peaked" solar signal (WMO 2011) in the tropics (peaks near $\sim 30 \mathrm{mb}$ and $\sim 5 \mathrm{mb}$, with a minimum near $\sim 10 \mathrm{mb}$ ). In the mesosphere, ozone response to SIM-based solar forcing is $\sim 3-4 \%$ compared to $\sim 1 \%$ of ozone response for the SATIRE modeled solar forcing.
There is a larger ozone response in low and middle stratosphere to SIM-based solar forcing compared to SATIRE forcing. This is similar to earlier modeling studies (e.g., Haigh et al. 2010; Merkel et al. 2011; Swartz et al. 2012; Shapiro et al. 2013; Dhomse et al. 2013; Ball et al. 2016). For the upper stratosphere, the earlier modeling studies do not all agree well with each other. Some studies (e.g., Haigh et al. 2010; Merkel et al. 2011; Swartz et al. 2012; Ball et al. 2016) show a reversal ozone response in the upper stratosphere and mesopshere for the out-of-phase solar forcing, whereas other studies show the reversal response to both forcing (e.g., Shapiro et al. 2013) or no reversal response to both forcing (e.g., Dhomse et al. 2013). Ozone response to both in-phase and out-of-phase in this modeling study does not have a reversal response in the upper stratosphere and mesosphere. Nevertheless, ozone responses to the two solar forcing scenarios are quite different in the stratosphere and mesosphere.

Using Halogen Occultation Experiment (HALOE) observations from 1991 to 2005, Remsberg (2008) found maximum ozone response on the order of $2-3 \%$ in the upper stratosphere 
G. Wen et al.: Climate responses to SATIRE and SIM-based spectral solar forcing in a 3D atmosphere-ocean coupled GCM
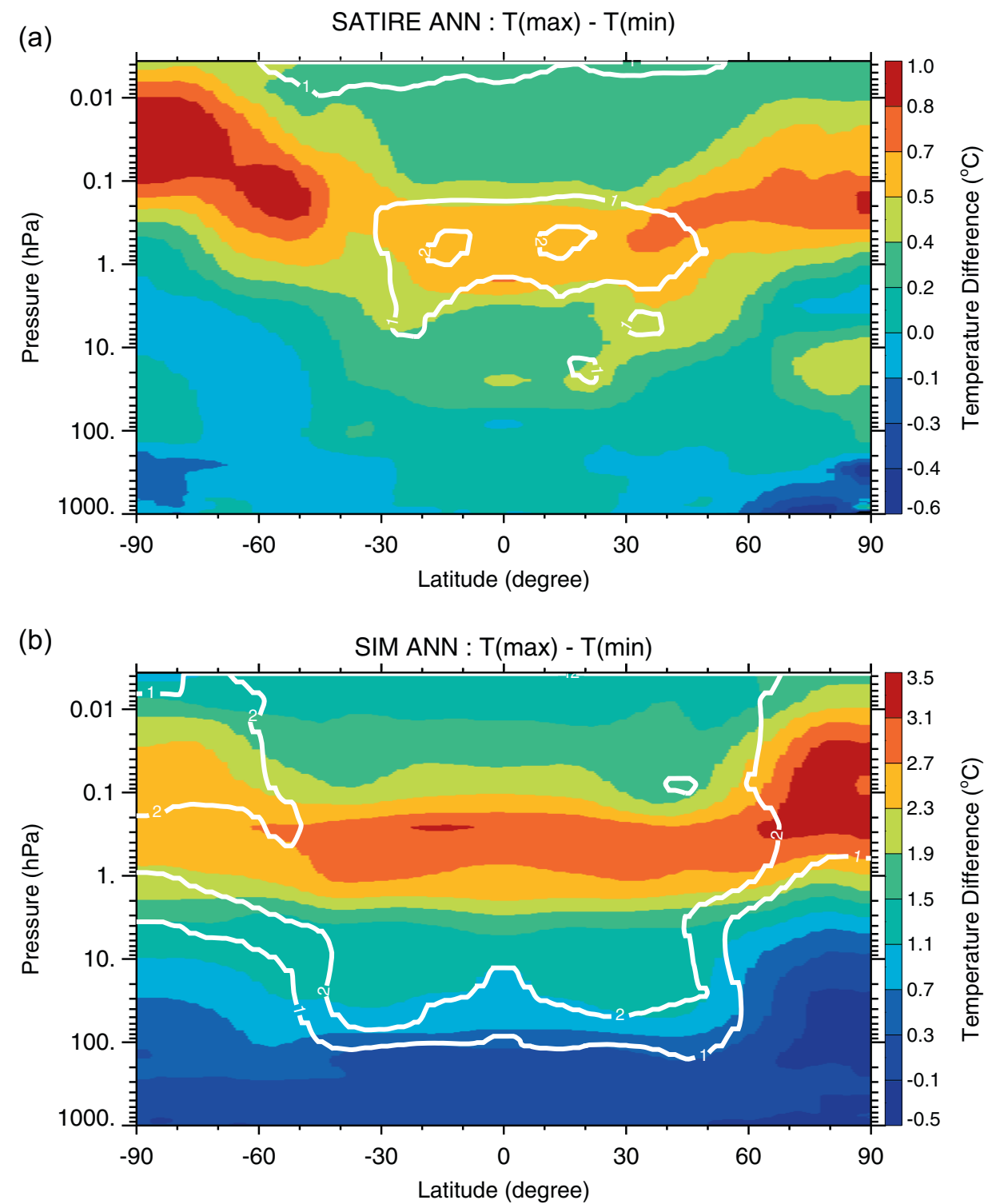

Fig. 9. (a) Average response of zonal-annual mean temperature to 11-year cycle of SATIRE forcing; (b) the response to SIM-based solar forcing.

at subtropical to middle latitudes. The average response to SATIRE forcing is about a half of HALOE observed response, whereas the average response to SIM-based forcing is about a factor of two of the observed ozone change.

Note we present the average responses of 16 solar cycles. The solar activity in earlier cycles is weaker than that in the Modern Maximum (1900 to present). Thus, average ozone response to SATIRE forcing would be closer to averaged observational based response if there has been such data available for the same time period. Similarly, average ozone response to SIM-based solar forcing would overestimate even more, were historical ozone response data available.

\subsection{Atmospheric temperature responses to 11-year solar activity}

The averages of zonal and annual mean temperature response to 11-year solar activity are presented in Figure 9 with significant level of one and two standard deviations indicated. The response to SIM-based solar forcing is significant at two standard deviations level in large part of regions of the atmosphere, from the middle to mesosphere in latitudes of $40{ }^{\circ} \mathrm{S}-40^{\circ} \mathrm{N}$. The response to SATIRE solar forcing is smaller and less significant compared to its counter part. The response at one standard deviation is near the stratopause and lower mesosphere in latitudes of $30{ }^{\circ} \mathrm{S}-40{ }^{\circ} \mathrm{N}$.

In tropics, the peak of the temperature response is about $0.5-0.7^{\circ} \mathrm{C}$ near $1 \mathrm{mb}$ for SATIRE solar forcing compared to $\sim 2{ }^{\circ} \mathrm{C}$ near $0.3 \mathrm{mb}$ for SIM-based solar forcing. The responses are similar to those reported in Swartz et al. (2012) (Fig. 8 in that study) except larger response and higher altitude of the peak for SIM-based forcing in this study. Observations from HALOE (peak value of $\sim 1{ }^{\circ} \mathrm{C}$ at $\sim 1 \mathrm{mb}$ ) (Remsberg 2008) suggest that the response to SATIRE forcing underestimates the temperature changes, whereas response to SIM-based forcing overestimates the temperature changes by a factor of two with a peak a higher altitude.

Again, as mentioned earlier, we present the average responses since 1833 after Dalton Minimum. HALOE observation may represent the response for Modern Maximum. 


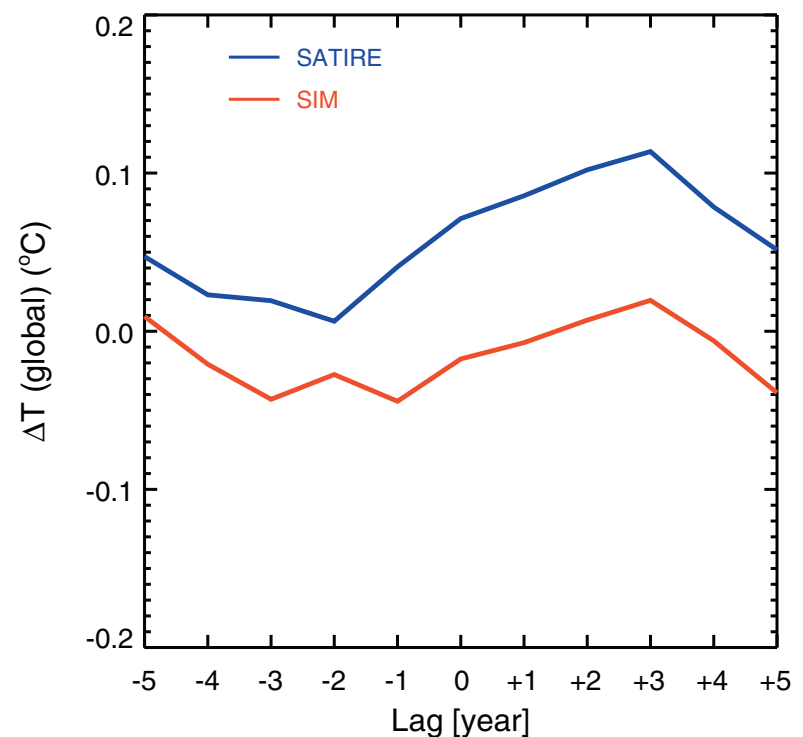

Fig. 10. Lagged solar regression coefficients of global mean air surface temperature for SATIRE (blue) and SIM-based (red) solar forcing. Positive lags mean that the solar forcing leads the response.

Were observation data available for the same time period, the average temperature response to SATIRE forcing would be closer to the average "observation", and the average temperature response to SIM-based forcing would be more than a factor of two than average "observation".

\subsection{Surface temperature responses to 11-year solar activity}

The regression coefficients for different time lags are presented for both in-phase and out-of-phase solar forcing in Figure 10. The global surface air temperature response to SATIRE forcing has a peak about $0.12{ }^{\circ} \mathrm{C}$ near the upper bound of those in Misios et al. (2015) (Fig. 2 in that study) and comparable to those $\left(0.08-0.16^{\circ} \mathrm{C}\right)$ from earlier studies (e.g., White et al. 1997; Tung \& Camp 2008; Douglass \& Clader 2002). The peaked global surface temperature response to SIM-based solar forcing is only about $0.02{ }^{\circ} \mathrm{C}$ near the lower bound those in Misios et al. Although both responses have similar shape, the signal for SATIRE forcing is significant at the $90 \%$ level, whereas the significance level for SIM-based solar forcing is only $40 \%$, so it is more likely $(60 \%)$ due to chance. Note the global average response lags the solar forcing by 3 years for both forcing scenarios, similar to four of the model results in Misios et al., and is about 1 year longer than the mean value of $1 \sim 2$ years in that study.

\section{Summary and discussion}

This paper investigates the climate responses to spectral solar forcing. We apply two reconstructed spectral solar forcing scenarios, one being an extrapolation of SIM observations, and a second one from the SATIRE model, as inputs to the GISS GCMAM, to examine climate responses on decadal and centennial time scales. We quantify the difference of the climate response to the two solar forcing scenarios.

We performed a detailed regression analysis. We find that for the SIM-based solar forcing, the global annual averaged stratospheric temperature responses are $2.34{ }^{\circ} \mathrm{C} /\left(\mathrm{W} \mathrm{m}^{-2}\right)$ at $2 \mathrm{mb}, 1.25^{\circ} \mathrm{C} /\left(\mathrm{W} \mathrm{m}^{-2}\right)$ at $15 \mathrm{mb}$, about six times as large as those for the SATIRE modeled in-phase solar forcing. This is because SIM SSI changes in the UV spectra are roughly six times as large as those for SATIRE SSI.

Near the tropopause at $100 \mathrm{mb}$, the global annual averaged stratospheric temperature response is $0.55^{\circ} \mathrm{C} /\left(\mathrm{W} \mathrm{m}^{-2}\right)$ for SIM-based solar forcing, about four times as large as that for the counterpart of SATIRE forcing. The much larger temperature response for SIM-based solar forcing is the result of a combination of excessive stratospheric heating and dynamic cause. To quantify the relative contribution of the two mechanisms to the temperature response (near the tropopause as well as at the surface) requires further analyses of finer temporal and spatial resolved simulations.

The global annual averaged surface temperature responses are small, about $0.13{ }^{\circ} \mathrm{C} /\left(\mathrm{W} \mathrm{m}^{-2}\right)$ and $0.05{ }^{\circ} \mathrm{C} /\left(\mathrm{W} \mathrm{m}^{-2}\right)$ for the SATIRE and SIM-based, respectively. From Maunder Minimum to present, there is an increase of $0.72 \mathrm{~W} \mathrm{~m}^{-2}$ in TSI, corresponding to $\sim 0.1{ }^{\circ} \mathrm{C}$ and $\sim 0.04{ }^{\circ} \mathrm{C}$ for the in-phase and out-of-phase forcing scenarios, respectively. To estimate the true contribution of the solar variability on climate since industrial revolution, however, GCM simulations with changes in trace gases, and emissions from volcanic eruptions are required to provide more accurate results.

Planetary albedo has a negative response resulting in a decreasing albedo trend on centennial and longer time scales for either solar forcing scenario. However, the mechanisms for the trends are completely different. The decreasing trend for SATIRE forcing is associated with a change in cloud cover. The decreasing trend for SIM-based solar forcing is not due to the change in cloud cover, but rather is due to the decrease in SW radiative forcing proxy and increase in TSI over the 400 years of GCM simulations.

For the SIM-based forcing scenario, large UV irradiance variation is accompanied by the out-of-phase SW radiative forcing change. SIM-based solar forcing induces large ozone and temperature responses in the stratosphere and mesosphere to the 11-year cycle as compared to the SATIRE solar forcing. This is similar to the findings of earlier studies (e.g., Haigh et al. 2010; Merkel et al. 2011; Swartz et al. 2012; Dhomse et al. 2013; Shapiro et al. 2013; Ermolli et al. 2013; Ball et al. 2016). The magnitude of the total ozone changes during the typical solar cycle in present time (more than 20 DU) suggests that the magnitude of the UV variability in SIM may have been largely overestimated (see Fig. 8 of Austin et al. 2008).

Note that the present study does not show reversal ozone response to either SIM-based or SATIRE solar forcing. This may be at least partially due to the limitation of LINOZ model in this region of the atmosphere (e.g., Geer et al. 2007).

Lagged surface air temperature response is a characteristic feature of the planet Earth due to large heat capacity of the oceans (Cahalan et al. 2010; Douglass \& Clader 2002; Gray et al. 2013; Misios et al. 2015; Tung \& Camp 2008; White et al. 1997). The global surface air temperature response to SATIRE 11-year forcing is about $0.12{ }^{\circ} \mathrm{C}$ lagging the solar forcing by 3 years and is significant. However, the 3 -year lagged temperature response to SIM-based solar forcing is insignificant. Thus SIM-like solar forcing induces an insignificant global surface temperature signal on multi-centennial and decadal timescales, and is inconsistent with current understanding of solar influences on climate.

This research is based on GISS GCMAM simulations for solar forcing only. To understand solar forcing on climate change, one needs to include changes in trace gases and 
G. Wen et al.: Climate responses to SATIRE and SIM-based spectral solar forcing in a 3D atmosphere-ocean coupled GCM

volcanic eruptions. While the details of the solar forcing contribution from these two solar wavelength distribution changes may well differ with the inclusion of these other effects, their predominant distinct differences (stratospheric and surface temperature response, ozone response) are likely to be maintained.

Acknowledgements. We thank two anonymous referees for their carefully reviewing the paper and making constructive comments as well as thank J. Lean, K. Kodera, J. Haigh, S. Ineson for helpful discussions. The editor thanks two anonymous referees for their assistance in evaluating this paper. This research was supported by NASA's Living With a Star program managed by Dr. M. Guhathakurta. Finally, we heartily thank the SORCE team for providing SIM data at http://lasp.colorado.edu/home/sorce/ data/ssi-data/.

\section{References}

Austin, J., K. Tourpali, E. Rozanov, H. Akiyoshi, S. Bekki, et al. Coupled chemistry climate model simulations of the solar cycle in ozone and temperature. J. Geophys. Res., 113, D11306, 2008, DOI: 10.1029/2007JD009391.

Ball, W.T., Y.C. Unruh, N.A. Krivova, S. Solanki, and J.W. Harder. Solar irradiance variability: a six-year comparison between SORCE observations and the SATIRE model. $A \& A, \mathbf{5 3 0}, \mathrm{A} 71$, 2011, DOI: $10.1051 / 0004-6361 / 20116189$.

Ball, W.T., J.D. Haigh, E.V. Rozanov, A. Kuchar, T. Sukhodolov, F. Tummon, A.V. Shapiro, and W. Schmutz. High solar cycle spectral variations inconsistent with stratospheric ozone observations. Nature, 9 (3), 206-209, 2016, DOI: 10.1038/ngeo2640.

Cahalan, R.F., G. Wen, J.W. Harder, and P. Pilewskie. Temperature responses to spectral solar variability on decadal time scales. Geophys. Res. Lett., 37, L07705, 2010, DOI: 10.1029/2009GL041898.

Douglass, D.H., and B.D. Clader. Climate sensitivity of the Earth to solar irradiance. Geophys. Res. Lett., 29, 1786, 2002, DOI: $10.1029 / 2002$ GL015345.

Dhomse, S.S., M.P. Chipperfield, W. Feng, W.T. Ball, Y.C. Unruh, D.J. Haigh, N.A. Krivova, S.K. Solanki, and A.K. Smith. Stratospheric $\mathrm{O}_{3}$ changes during 2001-2010: the small role of solar flux variations in a chemical transport model. Atmos. Chem. Phys., 13, 10113-10123, 2013,

DOI: $10.5194 /$ acp-13-10113-2013.

Ermolli, I., K. Matthes, T. Dudok deWit, N.A. Krivova, K. Tourpali, et al. Recent variability of the solar spectral irradiance and its impact on climate modeling. Atmos. Chem. Phys., 13, 3945-3977, 2013, DOI: 10.5194/acp-13-3945-2013.

Fontenla, J.M., J. Harder, W. Livingston, M. Snow, and T. Woods. High-resolutoin solar irradiance from extreme ultraviolet to far infrared. J. Geophys. Res., 116, D20108, 2011, DOI: $10.1029 / 211$ JD016032.

Frame, T., and L.J. Gray. The 11-yr cycle in ERA-40 data: an update to 2008. J. Climate, 23, 2213-2222, 2010, DOI: $10.1175 / 2009$ JCLI3150.1.

Geer, A.J., W.A. Lahoz, D.R. Jackson, D. Cariolle, and J.P. McCormack. Evaluation of linear ozone photochemistry parameterization in a stratosphere-troposphere data assimilation system. Atmos. Chem. Phys., 7, 939-957, 2007, DOI: $19.5194 /$ acp-7-939-2007.

Gray, L.J., J. Beer, M. Geller, J.D. Haigh, M. Lockwood, et al. Solar influence on climate. Rev. Geophys., 48, RG4001, 2010, DOI: $10.1029 / 2009$ GR000282.

Gray, L.J., A.A. Scaife, D.M. Mitchell, S. Osprey, S. Ineson, et al. A lagged response to the 11 year solar cycle in observed winter Atlantic/European weather patterns. J. Geophys. Res. Atmos., 118 (13), 405-13420, 2013, DOI: 10.1002/2013JD020062.

Haigh, J.D. The impact of solar variability on climate. Science, 272, 981-984, 1996, DOI: 10.1126/science.272.5264.981.
Haigh, J.D. The effects of solar variability on the Earth's climate. Philos. Trans. R. Soc. London, Ser. A, 361, 95-111, 2003, DOI: $10.1098 /$ rsta.2002.1111.

Haigh, J.D., A.R. Winning, R. Toumi, and J.W. Harder. An influence of spectral solar variations on radiative forcing of climate. Nature, 467, 696-699, 2010, DOI: 10.1038/nature09426.

Harder, J.W., J.M. Fontenla, P. Pilewskie, E.C. Richard, and T.N. Woods. Trends in solar spectral irradiance variability in the visible and infrared. Geophys. Res. Lett., 36, L07801, 2009, DOI: $10.1029 / 2008$ GL036797.

Hansen, J., G. Russell, D. Rind, P. Stone, A. Lacis, S. Lebedeff, R. Ruedy, and L. Travis. Efficient three-dimensional global models for climate studies: models I and II. Mon. Weather Rev., 111, 609-662, 1983, DOI: $10.1175 / 1520-0493(1983) 111<0609$ :ETDGMF>2.0.CO;2.

Hood, L.L., S. Misios, D.M. Mitchell, E. Rozanov, L.J. Gray, et al. Solar signals in CMIP-5 simulations: the ozone response. Q. J. R. Meteorol. Soc., 141, 2670-2689, 2015, DOI: 10.1002/qj.2553.

Ineson, S., A.A. Scaife, J.R. Knight, J.C. Manners, N.J. Dunstone, L.J. Gray, and J.D. Haigh. Solar forcing of winter climate variability in the Northern Hemisphere. Nat. Geosci., 4, 753-757, 2011, DOI: 10.1038/NGEO1282.

Kidston, J., A.A. Scaife, S.C. Hardiman, D.M. Mitchell, N. Butchart, M.P. Baldwin, and L.J. Gray. Stratospheric influence on tropospheric jet streams, storm tracks and surface weather. Nat. Geosci., 8, 433-440, 2015, DOI: 10.1038/ngeo2424.

Kodera, K., and Y. Kuroda. Dynamical response to the solar cycle: winter stratopause and lower stratosphere. J. Geophys Res., 107 (D24), 4749, 2002,DOI: 10.1029/2002JD002224.

Kopp, G., and J.L. Lean. A new, lower value of total solar irradiance: evidence and climate significance. Geophys. Res. Lett., 38, L01706, 2011, DOI: 10.1029/2010GL045777.

Kopp, G. An assessment of the solar irradiance record for climate studies. J. Space Weather Space Clim., 4, A14, 2014, DOI: $10.105 / \mathrm{swsc} / 2014012$.

Kopp, G. Magnitudes and timescales of total solar irradiance variability. J. Space Weather Space Clim., 6, A30, 2016, DOI: $10.1051 /$ swsc/2016025.

Krivova, N.A., L.E.A. Vieira, and S.K. Solanki. Reconstruction of solar spectral irradiance since the Maunder Minimum. J. Geophys. Res., 115, A12112, 2010,

DOI: $10.1029 / 2010 J A 015431$.

Lacis, A.A., and V. Oinas. A description of the correlated $\mathrm{k}$ distributed method for modeling nongray gaseous absorption, thermal emission, and multiple scattering in vertically inhomogeneous atmospheres. J. Geophys. Res., 96, 9027-9063, 1991, DOI: 10.1029/90JD01945.

Lacis, A.A., J.E. Hansen, G.L. Russell, V. Oinas, and J. Jonas. The role of long-lived greenhouse gases as principal LW control knob that governs the global surface temperature for past and future climate change. Tellus B, 65, 19734, 2013, DOI: 10.3402 /tellusb.v65i0.19734.

Lean, J. Evolution of the Sun's spectral irradiance since the Maunder Minimum. Geophys. Res. Lett., 27 (16), 2425-2428, 2000, DOI: 10.1029/2000GL000043.

Lean, J., and M.T. DeLand. How does Sun's spectrum vary? J. Climate, 25 (7), 2555-2560, 2012, DOI: $10.1175 /$ JCLI-D-11-00571.1.

Lee, J.N., R.F. Cahalan, and D.L. Wu. Solar rotational modulations of spectral irradiance and correlations with the variability of total solar irradiance. J. Space Weather Space Clim., 6, A33, 2016, DOI: $10.1051 / \mathrm{swsc} / 2016028$.

Matthes, K., Y. Kuroda, K. Kodera, and U. Langematz. Transfer of the solar signal from the stratosphere to the troposphere: northern winter. J. Geophys. Res., 111, D06108, 2006, DOI: $10.1029 / 2005 J D 006283$.

McClintock, W.E., G.J. Rottman, and T.N. Woods. Solar-Stellar Irradiance Comparison Experiment II (SOLSTICE II): instrument concept and design. Sol. Phys., 230, 225-258, 2005, DOI: $10.1007 / \mathrm{s} 11207-005-7432-x$. 
McLinden, C.A., S.C. Olsen, B. Hannegan, O. Wild, M.J. Prather, and J. Sundet. Stratospheric ozone in 3-D models: a simple chemistry and the cross-tropopause flux. J. Geophys. Res., 105, 14,653-14,666, 2000, DOI: 10.1029/2000JD90014.

Meehl, G.A., J.M. Arblaster, K. Matthes, F. Sassi, and H. van Loon. Amplifying the Pacific climate system response to a small 11 year solar cycle forcing. Science, 325, 1114-1118, 2009, DOI: $10.1126 /$ science. 1172872 .

Merkel, A.W., J.W. Harder, D.R. Marsh, A.K. Smith, J.M. Fontenla, and T.N. Woods. The impact of solar spectral irradiance variability on middle atmospheric ozone. Geophys. Res. Lett., 38, L13802, 2011, DOI: 10.1029/ 2011GL047561.

Misios, S., D.M. Mitchell, L.J. Gray, K. Tourpali, K. Matthes, et al. Solar signals in CMIP-5 simulations: effects of atmosphereocean coupling. Q. J. R. Meteorol. Soc., 142, 928-941, 2015, DOI: $10.1002 /$ qj.2695.

Mitchell, D., S. Misios, L.J. Gray, K. Tourpali, K. Matthes, L. Hood, H. Schmidt, G. Chiodo, R. Thieblemont, E. Rozanov, D. Shindell, and A. Krivolutsky. Solar signals in CMIP-5 simulations: the stratospheric pathway. Q. J. R. Meteorol. Soc., 141, 2390-2403, 2015, DOI: $10.1002 / \mathrm{qj} .2530$.

Oberländer, S., U. Langematz, K. Matthes, M. Kunze, A. Kubin, et al. The influence of spectral solar irradiance data on stratospheric heating rates during the 11 year solar cycle. Geophys. Res. Lett., 39, L01801, 2012,

DOI: $10.1029 / 2011$ GL049539.

Oinas, V., A.A. Lacis, D. Rind, D.T. Shindell, and J.E. Hansen. Radiative cooling by stratospheric water vapor: big differences in GCM results. Geophys. Res. Lett., 28, 2791-2794, 2001, DOI: 10.1029/2001GL013137.

Pawson, S., W. Steinbrecht, A.J. Charlton-Perez, M. Fujiwara, A.Yu. Karpechko, I. Petropavlovskikh, J. Urban, and M. Weber. Update on global ozone: past, present, and future, Chapter 2 In: Scientific Assessment of Ozone Depletion: 2014, Global Ozone Research and Monitoring Project - Report No. 55, World Meteorological Organization, Geneva, Switzerland, 2014.

Preminger, D., G. Chapman, and A. Cookson. Activity-brightness correlations for the Sun and Sun-like stars. Astrophys. J. Lett., 739, 6, 2011, DOI: 10.1088/2041-8205/739/2/L45.

Remsberg, E.E. On the response of Halogen Occultation Experiment (HALOE) stratospheric ozone and temperature to the 11-year solar cycle forcing. J. Geophys. Res., 113, D22304, 2008, DOI: 10.1029/2008JD010189.

Rind, D., J. Lerner, J. Perlwitz, C. McLinden, and M. Prather. Sensitivity of tracer transports and stratospheric ozone to sea surface temperature patterns in the doubled $\mathrm{CO}_{2}$ climate. J. Geophys. Res., 107 (D24), 4800, 2002, DOI: 10.1029/2002JD002483.

Rind, D., J. Lerner, J. Jonas, and C. McLinden. Effects of resolution and model physics on tracer transports in the NASA Goddard Institute for Space Studies general circulation models. J. Geophys. Res., 112, D09315, 2007, DOI: 10.1029/2006JD007476.

Rind, D., J. Lean, J. Lerner, P. Lonergan, and A. Leboissitier. Exploring the stratospheric/tropospheric response to solar forcing. J. Geophys. Res., 113, D24103, 2008,

DOI: $10.1029 / 2008 J D 010114$.
Rind, D., J. Lean, and J. Jonas. The impact of different absolute solar irradiance values on current climate model simulations. J. Climate, 27, 1100-1120, 2013, DOI: $10.1175 /$ JCLI-D-13-00136.1

Scafetta, N., and R. Willson. ACRIM total solar irradiance satellite composite validation versus TSI proxy models. Astrophys. Space Sci., 350 (2), 421-442, 2014, DOI: $10.1007 / \mathrm{s} 10509-013-1775-9$.

Schmutz, W., A. Fehlmann, W. Finsterle, G. Kopp, and G. Thuillier. Radiation processes in the atmosphere and ocean (IRS2012), AIP Conf. Proc., 1531, 624-627, 2013, DOI: 10.1063/1.4804847.

Shapiro, A.V., E.V. Rozanov, A.I. Shapiro, T.A. Egorova, J. Harder, M. Weber, A.K. Smith, W. Schmutz, and T. Peter. The role of the solar irradiance variability in the evolution of the middle atmosphere during 2004-2009. J. Geophys. Res. Atmos., 118, 3781-3793, 2013, DOI: 10.1002/jgrd.50208.

Shindell, D., D. Rind, N. Balachandran, J. Lean, and P. Lonergan. Solar cycle varibilty, ozone, and climate. Science, 284, 305-308, 1999, DOI: $10.1126 /$ science.284.5412.305.

Solanki, S.K., N.A. Krivova, and J.D. Haigh. Solar irradiance variability and climate. Annu. Rev. Astron. Astrophys., 51, 311-351, 2013, DOI: 10.1146/annurev-astro-082812-141007.

Swartz, W.H., R.S. Stolarski, L.D. Oman, E.L. Fleming, and C.H. Jackman. Middle atmosphere response to different descriptions of the 11-yr solar cycle in spectral irradiance in a chemistry-climate model. Atmos. Chem. Phys., 12, 5937-5948, 2012, DOI: $10.5194 / \mathrm{acp}-12-5937-2012$

Tung, K.K., and C.D. Camp. Solar cycle warming at the Earth's surface in NCEP and ERA-40 data: A linear discriminant analysis. J. Geophys. Res., 113, D05114, 2008, DOI: $10.1029 / 2007$ JD009164.

Unruh, Y.C., W. Ball, and N.A. Krivova. Solar irradiance models and measurements: a comparison in the $220-240 \mathrm{~nm}$ wavelength band. Surv. Geophys., 33, 475-481, 2012, DOI: $10.1007 / \mathrm{s} 10712-011-9166-7$.

Wang, S., K. Li, T.J. Pongetti, S.P. Sander, Y.L. Yung, et al. Mid-latitude atmospheric $\mathrm{OH}$ responses to the most recent 11-year solar cycle. PNAS, 110, 2023-2028, 2013, DOI: $10.10 .1073 /$ pnas. 1117790110 .

Wen, G., R.F. Cahalan, J.D. Haigh, P. Pilewskie, L. Oreopoulos, and J.W. Harder. Reconciliation of modeled climate responses to spectral solar forcing. J. Geophys. Res. Atmos., 118, 6281-6289, 2013, DOI: 10.1002 /jgrd.50506.

White, W., J. Lean, D.R. Cayan, and M.D. Dettinger. Response of global upper ocean temperature to changing solar irradiance. J. Geophys. Res. [Oceans], 102, 3255-3266, 1997, DOI: $10.1029 / 96 \mathrm{JC} 03549$.

WMO (World Meteorology Organization), Scientific assessment of ozone depletion: 2010. Global Ozone Research and Monitoring Project-Report No. 52, 516, Geneva, Switzerland, 2011.

Yeo, K.L., N.A. Krivoav, and S.K. Solanki. Solar cycle variation in solar irradiance. Space Sci. Rev., 186, 137-167, 2014, DOI: $10.1007 / \mathrm{s} 11214-014-0061-7$.

Zwiers, F.W., and H. von Storch. Taking serial correlation into account in tests of the mean. J. Climate, 8, 336-351, 1995, DOI: $10.1175 / 1520-0442(1995) 008<0336$ :tsciai $>2.0$.CO;2.

Cite this article as: Wen G, Cahalan RF, Rind D, Jonas J, Pilewskie P, et al. Climate responses to SATIRE and SIM-based spectral solar forcing in a 3D atmosphere-ocean coupled GCM. J. Space Weather Space Clim., 7, A11, 2017, DOI: 10.1051/swsc/2017009. 